Illinois State University

ISU ReD: Research and eData

Faculty Publications - Finance, Insurance, and

Law

Finance, Insurance, and Law

2015

\title{
Benefits of Lending Relationships in Public Debt Markets: Empirical Evidence from the Commercial Paper Market
}

\author{
David W. Blackwell \\ University of Kentucky \\ Vladimir Kotomin \\ Illinois State University, vkotomi@ilstu.edu \\ Drew B. Winters \\ Texas Tech University
}

Follow this and additional works at: https://ir.library.illinoisstate.edu/fpfil

Part of the Finance and Financial Management Commons

\section{Recommended Citation}

Blackwell, David W.; Kotomin, Vladimir; and Winters, Drew B., "Benefits of Lending Relationships in Public Debt Markets: Empirical Evidence from the Commercial Paper Market" (2015). Faculty Publications Finance, Insurance, and Law. 6.

https://ir.library.illinoisstate.edu/fpfil/6

This Article is brought to you for free and open access by the Finance, Insurance, and Law at ISU ReD: Research and eData. It has been accepted for inclusion in Faculty Publications - Finance, Insurance, and Law by an authorized administrator of ISU ReD: Research and eData. For more information, please contact ISUReD@ilstu.edu. 


\title{
Benefits from Lending Relationships in Public Debt Markets: Empirical Evidence from the Commercial Paper Market
}

\author{
David W. Blackwell, University of Kentucky \\ Vladimir Kotomin, Illinois State University \\ Drew B. Winters, Texas Tech University
}

\begin{abstract}
There is a large body of literature on the benefits of established lending relationships with banks, which is an intermediated debt market. We extend the literature by testing for benefits from direct lending relationships in the commercial paper market, which is a public debt market. Diamond (1991) suggests that firms access public debt markets when they have enough reputation to no longer require the close monitoring by banks. Using daily rate data for dealer-placed and directly placed commercial paper, we find that the year-end liquidity squeeze is less pronounced in the directly placed commercial paper than in the dealer-placed commercial paper, consistent with the existence of benefits from direct lending relationships in this public debt market.
\end{abstract}

Keywords: Lending Relationships, Commercial Paper 


\section{Benefits from Lending Relationships in Public Debt Markets: Empirical Evidence from the Commercial Paper Market}

\section{Introduction}

The global financial crisis has brought attention to the money markets with specific discussions related to their primary characteristics: low credit risk and high liquidity. As the first signs of the crisis were felt in the money markets in the summer of 2007, front-page articles in the Wall Street Journal discussed how investors have fled commercial paper for the safety of Treasury bills as the Federal Reserve pumped billions of dollars of additional liquidity in the market. Countrywide Financial Corporation (a large nationwide mortgage lender) was a prime example of the impact of the crisis on the commercial paper market as it drew on its bank lines of credit when it was unable to raise the necessary funds in the commercial paper market. These articles raise the question of how borrowers in the commercial paper market maintain access to credit during liquidity squeezes.

Diamond (1989) argues that borrowers develop reputation through repeated successful debt transactions with a bank, which allows them to reduce their loan rate over time. Diamond (1989) spawned a body of empirical literature on the value of lending relationships with the following being representative examples. Petersen and Rajan (1994) find that an ongoing relationship with a lender increases the amount of debt available to the borrower. Berger and Udell (1995) find that lending relationships reduce the rate charged to the borrower on a line of credit and reduce the need for collateral to support the line. Blackwell and Winters (1997) also find that lending relationships reduce the rate charged on lines of credit and reduce the monitoring efforts of the lender.

Lending relationships may benefit lenders, too. Yasuda (2005) finds that bank relationships have positive and significant effects on a firm's underwriter choice, and Bharath et al. (2007) find that 
relationship lenders' informational advantage allows them to sell more information-sensitive products to its borrowers.

Financial intermediaries such as banks do not suffer from lack of motivation to monitor their borrowers (as public debt market participants may) and thus are considered superior information producers and monitors. Diamond (1991) extends Diamond (1989) and argues that borrowers who develop sufficient reputation through successful transactions with a bank can leave the intermediated market and borrow directly in the public debt markets. Diamond (1991) does not discuss whether firms that borrow in the public debt markets can benefit from developing relationships with lenders in these markets. That is, can a borrower in a public debt market increase its access to debt and/or decrease its interest rate on debt by developing direct relationships with lenders? We examine this question by testing for the benefits from direct borrower-lender relationships in the public debt market for commercial paper (CP).

We take advantage of a well-defined year-end preferred habitat for liquidity (liquidity squeeze) (see, Griffiths and Winters (2005a)) in CP to examine whether a direct relationship with a CP purchaser (lender) provides better access to credit. We find that the year-end rate increase from the liquidity squeeze is smaller in magnitude and shorter in duration in directly placed than in dealerplaced CP. The smaller size and shorter duration of the squeeze in the directly placed CP market is consistent with the benefits of relationship lending. That is, borrowers who have direct relationships with their lenders are likely to have access to more debt at lower interest rates than other borrowers during periods of constrained liquidity. 
Our results may be compared to recent research findings on investment banking relationships for public debt issuers. ${ }^{1}$ However, investment banks are not lenders in these studies. We examine the value of borrower-lender relationships in public debt markets and find evidence to support the value of relationships when liquidity is constrained.

\section{Background}

\subsection{Experimental Setting and Testable Implications}

We examine whether firms that have sufficiently good credit quality to access the short-term public debt markets can benefit from developing direct relationships with lenders in these markets. We conduct our analysis in the commercial paper (CP) market. Here we detail why the CP market is an appropriate experimental setting for our analysis.

First, borrowers in the CP market have two ways to issue their paper (borrow). One way is "dealer-placed" CP which is issued by a borrowing firm and matched with an investor by a dealer. The second way is "directly placed" CP which is sold by a borrowing firm directly to the investor without the assistance of a dealer. Thus, borrowers in the commercial paper market can work either directly with lenders and develop relationships with them or through dealers and remain at arm's length from the lenders.

Second, we require an experimental setting where the potential benefits of borrower-lender relationships have an opportunity to work. Typically, this is accomplished with firm-level data. For example, Blackwell and Winters (1997) use the number of years a borrower has been with a bank as a proxy for the quality of the relationship, and Athavale and Edmister (2004) examine a time series of loan agreements between specific borrowers and their bank. Instead, we use aggregate market data for

\footnotetext{
${ }^{1}$ Fernando, May and Megginson (2012) find no evidence of relationships creating value for debt-issuing clients of Lehman Brothers. Burch, Nanda and Warther (2005) find that enhanced relationships between debt issuers and their investment banks lead to higher underwriting fees, consistent with a client lock-in effect.
} 
dealer-placed and directly placed commercial paper. Therefore, for our empirical analysis we need market-level events where the benefits of direct lending relationships have an opportunity to work. Griffiths and Winters (2005a) find that one-month CP rates increase at the year-end in a pattern that they suggest is consistent with a year-end preferred habitat for liquidity (liquidity squeeze). ${ }^{2}$ Thus, the CP market has a regular event associated with constrained credit availability where the benefits of borrower-lender relationships have an opportunity to work.

A preferred habitat for liquidity means that investors have strong maturity preferences in their investments so that the investments repay the investors (lenders) in time to meet their cash obligations. The year-end rate pattern identified by Griffiths and Winters (2005a) for 30-day commercial paper is that rates (1) increase at the turn of December, (2) remain abnormally high through most of December, and (3) return to normal across the turn of the year, with the decline beginning before the last trading day of the year. This rate pattern suggests that $\mathrm{CP}$ lenders have a preference for paper that matures toward the end of December and will only lend across the turn-of-the-year at abnormally high rates. Thus, there is a regular year-end "squeeze" in the CP market where lenders withdraw from some maturity dates and instead hold cash to meet their own year-end cash obligations. This squeeze is accompanied by rising $\mathrm{CP}$ rates.

Kane and Malkiel (1965) develop an analysis of borrower-lender relationships in an environment with constrained debt availability and show that banks benefit in both the short-run and long-run from granting the loan requests of their established customers (L-star customers). ${ }^{3}$ During liquidity squeezes lenders will accommodate some borrowers, but not all, and then generally at higher

\footnotetext{
${ }^{2}$ Musto (1997) also finds a year-end rate increase in the commercial paper market and suggests risk-shifting window dressing as the explanation. Griffiths and Winters (2005a) show that the year-end rate change pattern in commercial paper is not consistent with risk-shifting window dressing.

${ }^{3}$ Kane and Malkiel (1965) focus on loan requests from bank customers with deposit relationships. There are no deposit relationships in the commercial paper market.
} 
rates. The question is whether lenders would favor their regular borrowers with established relationships, and Kane and Malkiel (1965) provide a good reason to believe that they would.

Stigum (1990) notes that the largest group of lenders in the commercial paper market is money market funds (MMFs), which account for about 40 percent of the market. In addition, Stigum states that the vast majority of borrowers in directly placed $\mathrm{CP}$ are finance companies with average amounts outstanding of $\$ 6.7$ billion. Money market funds (the lenders) benefit from the ongoing demand of the finance companies (the borrowers), which allows MMFs to quickly and continually invest funds and avoid holding idle cash. Avoiding idle cash is vitally important to MMFs in generating the returns needed to compete for investors' dollars. Regular interactions between direct commercial paper issuers and buyers (MMFs) may introduce a type of quid pro quo. One benefit direct $\mathrm{CP}$ issuers can reasonably expect for regularly absorbing cash from MMFs is being able to continue borrowing in the $\mathrm{CP}$ market during the year-end liquidity squeeze as an accommodation in their direct relationships with lenders. Kotomin, Smith, and Winters (2014) find that MMFs tend to have significant net outflows in the last two weeks of the year, as investors appear to move money into bank demand deposits for year-end disbursements. MMFs facing net outflows will be more selective in choosing investments and are likely to drop their "marginal" investments.

Therefore, the commercial paper market provides an appropriate experimental setting for analyzing the potential benefits of direct lender-borrower relationships in the public debt markets. If direct borrowers benefit from their relationships with lenders in the CP market, they should have access to more credit and/or enjoy lower rates than other borrowers during the year-end liquidity squeeze. Since we work with market-level data, we cannot directly test whether direct borrowers have access to more credit. However, if direct borrowers have access to more credit, the duration of the year-end liquidity squeeze should be shorter for them than other borrowers. In addition, when rates 
increase prior to the year-end, we expect to find smaller rate increases for direct borrowers than for other borrowers.

Before moving on, we need to explain our choice of the sample period. In the previous section we cite Stigum (1990) which provides an excellent discussion of industry practices and statistics but may appear outdated. However, our sample period covers from January 1983 through December 1996. The sample ends in 1996 because during 1997 the Fed changed the process for collecting and reporting CP data and no longer provided the breakdown of dealer-placed vs. directly placed CP rates. Accordingly, we will cite Stigum (1990) throughout this paper to provide market details characterizing the sample period.

\subsection{Important Features of the Commercial Paper Market}

In this section we discuss institutional details of the commercial paper market that we believe will provide useful context for our analysis.

We begin with the dollar size of the market. The volume of outstanding CP increased steadily from less than $\$ 194$ billion at the beginning of 1984 to $\$ 775$ billion at the end of 1996 , the end of our sample period. ${ }^{4}$ The annualized rate of growth between 1984 and 1996 is over 11\%. These numbers suggest that the $\mathrm{CP}$ market was large and grew at a significant rate across our sample period.

Commercial paper is available in initial maturities from 1 to 270 days. A majority of $\mathrm{CP}$ is issued with an initial maturity of 30 days or less. Approximately $85 \%$ of $\mathrm{CP}$ issuers sell their paper through dealers. The other 15\% directly issue their CP (Stigum 1990). Traditionally, the direct issuers of $\mathrm{CP}$ are large corporations and financial institutions with significant levels of outstanding paper.

\footnotetext{
${ }^{4}$ Earlier we noted that money market funds account for about $40 \%$ of the lending in the commercial paper market. At $40 \%$, money market funds would be lending $\$ 78$ billion at the beginning of our sample period and $\$ 310$ billion by the end of it.
} 
Two primary reasons exist for the use of dealers. The first is the substantial cost of establishing the systems and hiring the people needed to directly place $\mathrm{CP}$. The second is the time required to develop the relationships necessary to the success of a direct placement CP program. Obviously, the issuers selling through dealers do so because dealers have the systems, people, and relationships needed to successfully place CP.

There are two primary disadvantages to using dealers to place CP. The first one is that the issuer is a price taker in the dealer-placed CP market. The dealer surveys the market each morning and then offers the price to the issuer. The second disadvantage of using a dealer is that the issuer has no idea who holds their CP. This creates concentration risk for the issuer, which exposes it to adverse effects from a credit market event. Direct relationships may mitigate this risk (Kane and Malkiel (1965)).

Stigum (1990) notes that in the late 1980s (the middle of our sample period) $43 \%$ of issued CP by volume was placed directly. Stigum's Panel A of Table 22-1 (p.1060) lists the 17 largest direct issuers of $\mathrm{CP}$ and provides their $\mathrm{CP}$ rating and dollar amounts outstanding. Fourteen of the 17 largest direct issuers of $\mathrm{CP}$ were rated $\mathrm{A}-1 / \mathrm{P}-1$ which is the top credit rating for $\mathrm{CP}$ and is similar to the AArating for bonds. The three companies not receiving an A1/P1 rating were Beneficial Corp, Chrysler Financial, and John Deere Credit.

Finally, the effective annual interest rate on $\mathrm{CP}$ is calculated as follows:

Discount $=$ Discount rate $*$ Face $*($ days to maturity/360)

Usable funds $=$ Face - Discount

Effective annual rate $=\frac{\text { Discount }+ \text { Dealer Fee }+ \text { Backup Fee }}{\text { Usable Funds }} * \frac{365}{\text { Days to Maturity }}$

A dealer fee (typically $1 / 8^{\text {th }}$ of a percentage point during our sample period) can be thought of as an underwriting fee. Directly placed CP does not pay a dealer fee. Also, the directly placed CP rate is not 
an all-in cost of CP because it does not include the costs of systems and people to run a direct placement program. These costs are substantial. Stigum (1990) notes that to make direct placement economically feasible, the issuer would need to average at least $\$ 1$ billion in outstanding CP.

However, Stigum also notes that for large issuers economies of scale may result in substantial benefits. One large issuer calculates the cost of its direct placement program at 1 basis point. Another issuer of directly placed paper suggests that if direct costs are 5 to 6 basis points, the issuer is likely better off going through dealers than issuing directly. The backup fee is for the back-up line of credit from a bank that investors require on CP. Dealer-placed paper typically carries $100 \%$ back-up to ensure the availability of credit. Some of the large direct issuers of CP such as GMAC did not carry 100\% backup.

\section{Data and Methods}

\subsection{Data}

Our sample includes 3,498 average daily commercial paper rates for both 30-day and 90-day paper from the beginning of 1983 through the end of 1996. During this time period, CP rates were collected by the Federal Reserve and reported under one of two classifications: directly placed commercial paper and dealer-placed commercial paper.

We chose to start our sample in 1983 to avoid the unusually volatile period in interest rates from October 1979 through October 1982 when the Federal Reserve experimented with targeting M1. We capped our sample at the end of 1996 due to a change in the way CP rates were being reported that took place on September 1, 1997. Prior to that date, the Federal Reserve collected CP rates via survey. The Federal Reserve would survey a sample of firms who placed their $\mathrm{CP}$ issues directly with investors, as well as a sample of dealers that employed brokers to place $\mathrm{CP}$ issues on behalf of firms 
that did not sell CP directly to investors. The Federal Reserve would then average these daily rates and report them as directly placed and dealer-placed commercial paper rates for the appropriate maturities.

Starting on September 1, 1997 the Federal Reserve turned over the stewardship of collecting daily rates to the Depository Trust Company (DTC) of New York City. ${ }^{5}$ The DTC is a national clearinghouse for the settlement of securities trades and performs this function for nearly all domestic commercial paper activity. The $\mathrm{CP}$ rates would be collected throughout the day, averaged, and electronically submitted to the Federal Reserve for reporting. The benefits include more accurate reporting and savings of costs of conducting the surveys. However, the Federal Reserve now reports the rates for financial and non-financial CP rather than dealer-placed and directly placed CP. Since there is overlap between the two classifications, we end our sample at the end of the last full year in which the Federal Reserve conducted the surveys to make the comparisons needed between dealerplaced and directly placed $\mathrm{CP}^{6}$

\subsection{Descriptive Statistics}

Table 1 reports basic descriptive statistics for the data used in the analysis. Panel A provides average rates for each series of commercial paper data and for three-month T-bills yields. We include three-month T-bill rates to provide a reference point for the commercial paper rates and because we use the three-month T-bill yield as a proxy for the general level of short-term interest rates. The average three-month T-bill yield across the sample period is $6.155 \%$. We find that the average T-bill

\footnotetext{
${ }^{5}$ In May of 1997, the Federal Reserve issued a memo explaining the changes in which the commercial paper rates would be collected. "A Change in the Source of Commercial Paper Data Published by the Federal Reserve System," May 12, 1997, http://www.federalreserve.gov/releases/H15/cp.htm

${ }^{6}$ We have contacted the DTC about more current data. We were told that the DTC does not archive CP data and that the cost of recovering old data would be prohibitive. We have contacted researchers at the Federal Reserve about access to more detailed data underlying the summary data made available through the FRB data download system. We have been unable to gain access to this data, which prevents the use of more current data in this study.
} 
yield in December is statistically lower (albeit only at the $10 \%$ level of significance) than the average rate for the other eleven months, which supports the need to control for the general level of interest rates in later analyses. ${ }^{7}$ The average rates for 30-day dealer-placed CP increase in December, which is consistent with the year-end preferred habitat for liquidity in commercial paper identified by Griffiths and Winters (2005a). The 30-day directly placed CP rate and the 90-day dealer-placed CP rate change very little, and the 90-day directly placed CP rate decreases in December, although not significantly. The decrease is consistent with benefits for direct lending relationships in the $\mathrm{CP}$ market.

Panel B of Table 1 reports spreads between dealer-placed and directly placed commercial paper rates. From January through November, the rate on 30-day dealer-placed CP is on average about nine basis points higher than the rate on 30-day directly placed CP. However, in December this spread increases to over 23 basis points. In the 90 -day CP, the average spread from January through November is 17 basis points, and it increases in December to almost 30 basis points. We draw two insights from these spreads. First, in Section 2 we cited Stigum's (1990) observation that if an issuer's direct costs are 5 to 6 basis points, the issuer is likely better off going through dealers than issuing directly. Our average spreads of 10 basis points on 30-day commercial paper and 18 basis points on 90-day commercial paper are consistent with this observation. Second, the further increase in the dealer-placed CP rate relative to the directly placed CP rate during the year-end liquidity squeeze is consistent with the value of lender-borrower relationships and suggests that these relationships have value even in the short-term public debt markets.

Figure 1 plots average spreads between CP rates and the three-month T-bill rate (Panel A) and between dealer-placed and directly placed CP rates (Panel B) for each trading day in the year from day 1 to 250 (i.e., these are averages over the 14 years in the sample period). We present Panel B in

\footnotetext{
7 The lower December yield is surprising because both Musto (1997) and Griffiths and Winters (2005a) analyze threemonth T-bill yields for a year-end effect and both find no effect.
} 
addition to Panel A because T-bills tend to have somewhat lower yields in December (see Table 1), and we want to ensure that the year-end effect in the dealer-place CP is not due to this decline in T-bill yields. It is clear from Figure 1 that changes in the spreads around the turn of the year are economically significant. Further analysis is needed to determine whether these changes are statistically significant.

We are examining the value of lending relationships by examining the year-end preferred habitat for liquidity in CP. We have market-level data. We do not have access to firm-level data, so there could be concerns about differing risk between dealer-placed paper and directly placed paper. ${ }^{8}$ Stigum (1990, figure 22-5) shows the 75.9\% of CP issuers (number of issuers, not dollar volume) during our sample period are rated A1/P1. Further, Stigum (1990) notes that following the failure of Penn Central Transportation Company (June 21, 1970) that CP lenders wanted borrowers of unimpeachable credit quality. Finally, asset-backed CP was less than $10 \%$ of the total CP market until 1995. Accordingly, during our sample period the CP market is characterized by high quality borrowers of relatively homogeneous credit risk, so there is no reason to expect a systematic difference in risk between $\mathrm{CP}$ borrowers that directly place their paper and $\mathrm{CP}$ borrowers that place their paper through dealers. We provide further details on credit risk in section 5 below.

\subsection{Methods of Analysis}

Griffiths and Winters (2005a) discuss that their methods allow for identifying the size and timing of the year-end effect in commercial paper. Since we are also testing for the size and timing of

\footnotetext{
${ }^{8}$ The CP in our sample qualifies for the registration exemption under Section 3(a) (3) of the 1933 Securities Act. This means that there are not filings with the SEC for the individual securities underlying our data. Kacperczyk and Schnabl (2010) report that in 1990 about $34 \%$ of the CP market was non-financial CP with $60 \%$ in financial CP. The remaining 6\% was ABCP. Financial CP is typically issued by subsidiaries of banks or captive finance companies, which do not have separate financial statements to allow an issuer-level analysis. With these data restrictions any firm-level analysis would be severely limited and would raise concerns about generality.
} 
a year-end effect in commercial paper, we apply similar methods in our analysis. Specifically, we employ regressions of daily rate (spread) changes and the calculation of day-by-day average spreads around the end of the year. We discuss both methods in this section.

Our first regression model is the following OLS with White's (1980) adjustment for heteroskedasticity:

$$
\Delta R_{t}=a_{0}+a_{1} \Delta \text { Tbill } t_{t}+\alpha_{2} \text { JanEnd }+\alpha_{3} \text { FebBgn }+\cdots+a_{22} \text { NovEnd }+a_{23} \text { DecBgn }+a_{24} \text { YrEnd }+a_{25} \text { YrBgn }
$$

where:

$\Delta R_{t}=\quad$ daily change (i.e., $\mathrm{R}_{\mathrm{t}}-\mathrm{R}_{\mathrm{t}-1}$ ) in commercial paper rate of a given type (dealer- or directly placed) and maturity (30 or 90 days), in basis points,

$\Delta$ Tbill $_{t}=\quad$ daily change in the three-month T-bill rate, Tbill $_{t}-$ Tbill $_{t-1}$, in basis points,

JanEnd $=\quad$ a $0 / 1$ dummy that equals 1 for the last two trading days of January and 0 otherwise; FebEnd, MarEnd, etc. are defined similarly for other months except December,

FebBgn $=\quad$ a 0/1 dummy that equals 1 for the first two trading days of February and 0 otherwise; MarBgn, AprBgn, etc. are defined similarly for other months except January,

YrEnd $=\quad$ 0/1 dummy variable that equals 1 for the last two trading days of December and 0 otherwise,

$\operatorname{YrBgn}=\quad$ 0/1 dummy variable that equals 1 for the first two trading days of January and 0 otherwise.

The time subscripts are suppressed for the dummy variables.

Our second regression model is also an OLS with the White's adjustment for heteroskedasticity:

$$
\Delta S p r_{t}=a_{0}+\alpha_{1} \text { JanEnd }+\alpha_{2} \text { FebBgn }+\cdots+a_{21} \text { NovEnd }+a_{22} \text { DecBgn }+a_{23} \text { YrEnd }+a_{24} \text { YrBgn }
$$

where $\Delta \operatorname{Spr}_{t}$ is the daily change in the spread between the dealer-placed and directly placed $\mathrm{CP}$ of the same maturity, in basis points. The independent variables in Equation (2) are the turn-of-the-month dummy variables defined above for Equation (1). The regression models are designed to capture rate or spread changes at the turn of each month, including the turn of the year. The augmented Dickey- 
Fuller test rejects the null of non-stationarity for all CP rate and spread changes. The 3-month T-bill yield change in Equation (1) is a control for changes in the general level of short-term interest rates. ${ }^{9}$ To be consistent with the year-end preferred habitat for liquidity, the 30-day CP rate should go up on the last two days of November and/or the first two days of December (i.e., the hypothesized sign of the NovEnd and/or DecBgn dummies is positive) and go down on the last two days of the year and possibly continue to go down on the first two days of the next year (i.e., the hypothesized sign of the YrEnd and YrBgn dummies is negative). However, to support a preferred habitat for liquidity at the year-end for a 30-day instrument, spreads should remain high across December, so additional analysis is needed. In particular, we compare the average spread between dealer-placed and directly placed CP rates for each trading day from day -25 to +5 relative to the year-end with the average spread on all other days. This day-to-day spread analysis allows us to examine the duration of the year-end effect.

\section{Empirical Results}

\subsection{Regression Analysis of Daily Commercial Paper Rate and Spread Changes}

Panel A of Table 2 provides results from four different estimations of Equation (1). The first estimation is for 30-day dealer-placed commercial paper. In this estimation the dependent variable is the daily change (i.e., the first difference) in the 30-day dealer-placed CP rate. The second estimation is for 30-day directly placed commercial paper rate changes. The third and fourth estimations capture the daily rate changes in the 90-day dealer-placed and 90-day directly placed CP, respectively.

The key calendar break points for 30-day CP are the turn of December (captured by the NovEnd and DecBgn dummies) and the turn of the year (the YrEnd and YrBgn dummies). In the

\footnotetext{
${ }^{9}$ Running the regressions without the T-bill yield change on the right-hand side does not affect the calendar-time results but causes the adjusted R-squareds of the regressions to fall notably. Since T-bill yields reported in Table 1 appear to be lower in December, we also ran a specification with both the T-bill change and the T-bill change interacted with the December variable on the right-hand side. Introducing the interaction term does not affect the results in any meaningful way. (The results are not reported for brevity.)
} 
regression for 30-day dealer $\mathrm{CP}$ rate changes, the largest absolute parameter estimates are for the first two days of December, DecBgn, and the turn of the year, YrEnd and YrBgn. Because each dummy variable covers two consecutive days in a given year, their estimated coefficients are interpreted as CP rate changes on each of the two days covered by the dummy. For example, the 30-day dealer-placed $\mathrm{CP}$ rate increases by $2.8 \mathrm{bps}$ on each of the last two days of November and by $14.7 \mathrm{bps}$ on each of the first two days of December, for the total turn-of-December increase of 35bps. It then decreases by $6.8 \mathrm{bps}$ on each of the last two days of the year and by $18.2 \mathrm{bps}$ on each of the first two days of the next year, for the total effect of 50bps. This rate change pattern is consistent with the year-end preferred habitat for liquidity. We also observe positive coefficients at the end of March, June, and September, followed by negative parameters at the beginning of April, July, and October, respectively, consistent with some pressure to borrow at quarter-ends and abatement of such pressure after the quarter-end. These rate changes are much smaller in absolute values than the year-end changes.

Directly placed 30-day CP (the second set of results in Panel A of Table 2) exhibits year-end rate changes similar to the dealer-placed paper: the rates increase around the turn of December and fall around the turn of the year. Again, these results are consistent with a preferred habitat for liquidity at the year-end. The turn-of-December coefficients (NovEnd and DecBgn) indicate that the total increase in the rate over four days is $29.6 \mathrm{bps}$ (3.1bps on each of the last two days of November and $11.7 \mathrm{bps}$ on each of the first two days of December). It is slightly smaller than the total increase in the dealerplaced 30-day CP rate of 35bps. The turn-of-the-year coefficients, YrEnd and YrBgn, are also smaller in absolute value than their dealer CP counterparts. The turn-of-the-year total decline in the 30-day direct CP rate is about 23bps (5.2bps on each of the last two days of the year, followed by $6.3 \mathrm{bps}$ on each of the first two days of the year), falling a bit short of fully offsetting the turn-of-December spike 
of 29.6bps. In the dealer-placed 30-day CP, however, the total turn-of-the-year rate decline of 50bps exceeds the turn-of-December spike of 35bps.

Combined with Figure 1, the results of the first two regressions suggest that the 30-day dealerplaced CP rate increases not only around the turn of December but also later in the month, while directly placed paper rates spike only at the turn of December. Both types of CP rates then return to "normal", pre-December, levels after the turn of the year. The additional increase in the dealer CP rates later in December is consistent with borrowers facing more difficulty in placing their paper during the year-end liquidity squeeze. The direct CP issuers do not face this additional pressure, which is consistent with the benefits of direct lending relationships. The analysis of day-by-day spreads in the next subsection (4.2) will help determine whether it is the case.

The third set of results in Panel A of Table 2 is for the changes in the 90-day dealer-placed CP rate. There are no significant rate increases at the beginning of October (when the 90-day maturity starts spanning the end of the year) or December. ${ }^{10}$ The end-of-November increase of $3.7 \mathrm{bps}$ per day on two days is more than offset by significant rate declines around the turn of the year, suggesting a preceding increase that may be too gradual to be fully captured by dummy variables covering only four days at turns of months.

The last set of results in Panel A of Table 2 is for 90-day directly placed CP rate changes. There is a slight increase in the rates on the last two days of November but no significant rate changes around the end of the year. It is consistent with direct borrowers in the 90-day CP market not facing a

\footnotetext{
${ }^{10}$ Because 90 calendar days is usually less than three months, we have also run the 90 -day CP regressions with the dummy variable covering the last two trading days before the 90-day CP maturity starts to span the end of the year in place of SepEnd and the dummy variable covering the first two days after the 90-day CP maturity starts to span the end of the year in place of OctBgn. These alternative dummy variables always have statistically insignificant coefficients, and do not seem to affect other estimated parameters; therefore, we choose to retain SepEnd and OctBgn variables in the regression results we report.
} 
liquidity squeeze to the same degree as dealer-placed and directly placed $\mathrm{CP}$ issuers in the 30-day $\mathrm{CP}$ as well as dealer-placed CP issuers in the 90-day CP.

Panel B of Table 2 supplements the results in Panel A by reporting the output of Equation (2) for changes in the spreads between dealer-placed and directly placed commercial paper rates. It is designed to determine if the relationships developed through placing CP directly significantly reduce the rate impact of the year-end liquidity squeeze for the borrowers in this market. If they do, we would expect positive parameter estimates on NovEnd and/or DecBgn followed by negative parameter estimates on YrEnd and/or YrBgn in the 30-day paper. We find that NovEnd, DecBgn, and YrEnd are insignificant, while $\operatorname{YrBgn}$ is negative and significant at the $10 \%$ level in the 30 -day maturity. As to the spread between 90-day dealer- and directly placed CP rates (the last column in Table 2), it does not increase around the turn of October or December but decreases significantly both on the last two and the first two trading days of the year. ${ }^{11}$

Our regressions apparently do not fully capture the build-up in the rates and spreads prior to the end of the year. To supplement our regression analysis and to take a deeper look at the month of December and the turn of the year, we now turn to the day-by-day spread analysis for trading days -25 to +5 relative to the year-end.

\subsection{Day-by-day Analysis of Commercial Paper Spreads around the Turn of the Year}

Our regression results are consistent with a year-end preferred habitat for liquidity. However, to fully support a preferred habitat at the year-end in 30-day commercial paper, the rate increase at the

\footnotetext{
11 The results in Panel B are somewhat redundant. Since spread changes are simply differences between the respective rate changes (e.g., a 30-day spread change is the change in the 30-day dealer $\mathrm{CP}$ rate minus the change in the 30-day direct $\mathrm{CP}$ rate), the coefficients in the first (second) column of Panel B are roughly the differences between the coefficients in the first and second (third and fourth) output columns in Panel A.
} 
turn-of-December must persist across the month. The day-by-day spread analysis allows us to determine if it occurs and also to determine if the relationship effect exists in directly placed CP.

Table 3 presents four sets of spreads for trading days -25 to +5 relative to the year-end. The spreads are between 30-day dealer-placed CP and three-month T-bill rates, 30-day directly placed CP and three-month T-bill rates, 30-day dealer-placed and directly placed CP rates , and 90-day dealerplaced and directly placed CP rates, respectively. We first compute each of these spreads for each trading day in our sample. Then for each trading day from -25 to +5 relative to the year-end (our chosen turn-of-the-year window) we calculate the average daily spread over the sample period (e.g., the average dealer-direct 30-day CP spread on day -25 is the average of all such spreads on day -25 over the 14-year study period). There is no day 0 . We then employ a two-tailed t-test for mean equality between the average spread on each day in the turn-of-the-year window and the average spread on "regular" days (all the days not in the turn-of-the-year window of days- 25 to +5 relative to the yearend). We report the test results in the table. For instance, the average spread between 30-day dealerplaced $\mathrm{CP}$ and three-month T-bill rate on day -14 relative to the year-end is $76.9 \mathrm{bps}$, which is different from the average spread on "regular" days of $49.9 \mathrm{bps}$ (reported in the first row) at the $1 \%$ level.

The day-by-day spreads over the T-bill rate reported in Table 3 suggest that the year-end liquidity squeeze results in sustained spread increases throughout December in both dealer-placed and directly placed CP over T-bills. ${ }^{12}$ The month of December has 20, 21 or 22 business days. Thus, the dramatic increase in the spreads around trading day -21 roughly coincides with the first business day of December, which is consistent with the regression results reported in Panel A of Table 2. Also, note that we are examining a 30-day instrument and not a one-month instrument, so investors buying 30-day CP on the last trading day of November would be buying securities maturing on December 30.

\footnotetext{
12 This result is not driven by a slight decline in the three-month T-bill rate prior to the end of the year (see Table 1).
} 
Commercial paper maturing on December 30 provides liquidity before the end of the year because CP transactions settle in immediately available funds.

The spread increases in 30-day direct CP rate over the T-bill rate (the second set of spreads reported in Table 3) are smaller than the spread increases in the dealer-placed CP rates over the T-bill rate. To determine whether the dealer-direct CP spread increases significantly prior to the end of the year, we turn to the last two columns of Table 3. We observe that the dealer-direct $\mathrm{CP}$ spreads are abnormally high across December. They are both statistically and economically larger than the average spreads on all other days (reported in the top row). The spreads return to normal levels by the beginning of the New Year in both maturities. Notice that the spread is also consistently above "normal" on most of days in December even in the 90-day maturity. That is, during the year-end liquidity squeeze in the commercial paper market, the rates on dealer-placed $\mathrm{CP}$ increase significantly more than the rates on directly placed $\mathrm{CP}$ in both 30-day and 90-day maturities. It suggests that benefits exist in the commercial paper market from developing direct relationships with lenders.

Panel A of Figure 2 plots differences in the average spread between 30-day commercial paper rates and three-month T-bill rates on each of the trading days from -25 to +5 and the average spread on all other days. Panel B of Figure 2 plots similarly defined spread differences between dealer-placed and directly placed CP rates. That is, we take the spreads on days from -25 to +5 in Table 3 and subtract the spread on "regular" days from them. That is, the spread difference on Day -20 for the spread between 30-day dealer-place CP and three-month T-bill rates in Figure 2A appears to be just below 30bps. Referring to the first column of spreads in Table 3, we see that the average spread on Day -20 between the 30-day dealer-place CP and three-month T-bill rates is 78.6bps and the average spread on all other ("regular") days is $49.9 \mathrm{bps}$; the difference in the spreads is $28.7 \mathrm{bps}$, which is what we see in the figure. 
Overall, the results for 30-day commercial paper suggest that the year-end liquidity squeeze is present in both dealer-placed and directly placed paper. However, the magnitude of the effect is economically and statistically smaller in the directly placed $\mathrm{CP}$, consistent with the benefits from direct lender-borrower relationships in this short-term public debt market. Analysis of the spreads between 90-day dealer-placed and directly placed CP rates corroborates the 30-day results.

\section{Potential Concerns, Data Limitations and a Post-Crisis Comment}

Our results are based on market-level data. Firm-specific data are not currently available. Thus, reasonable concerns exist that the findings are driven by dealer-placed $\mathrm{CP}$ issuers being different from direct $\mathrm{CP}$ issuers (e.g., in terms of industries, credit quality, or size). We discuss the concerns and explain why we believe the overall $\mathrm{CP}$ market is sufficiently homogeneous relative to firm-specific factors for us to draw conclusions from market-level data.

First, directly placed $\mathrm{CP}$ was dominated by financial issuers (bank subsidiaries and captive finance companies) during our study period, a potential concern is that investors may consider financial CP safer, more liquid, or both, implying that the spread between directly and dealer-placed CP rates could be explained by differences in issuers' characteristics rather than by lending relationships. To alleviate this concern, we examine the spreads between AA-rated financial and AArated non-financial CP rates in the first six years after the end of our sample, 1997-2002 (the Fed has reported financial and non-financial CP rates since 1997). The average spread for the 30-day (90-day) $\mathrm{CP}$ is 1.6 (2.5) basis points. Thus, the financial CP rates are, on average, higher than rates on similarly rated non-financial paper, which is inconsistent with financial $\mathrm{CP}$ being perceived as safer, or more liquid, than non-financial paper. It also means that it is harder to find relationship benefits for direct 
issuers if financial firms (who dominated the direct CP market) have to offer slightly higher yields than similarly rated non-financial issuers. ${ }^{13}$

Second, credit quality of most issuers in the CP market is high or very high. Investors in the money markets are concerned with the return of principal more than the return on principal, due to the temporary nature of their excess cash. More than $95 \%$ of issuers have been in the top two CP rating categories, A1/P1 and A2/P2. Firms with lower credit quality will have to borrow short-term funds from intermediaries such as banks. Of course, the A2/P2-rated paper has higher yields than the A1/P1rated paper. Griffiths and Winters (2005b) find that the spread between 30-day A2/P2 and A1/P1-rated paper increases at the turn of December, consistent with the higher price of credit risk during periods of constrained liquidity. However, this credit spread does not show an additional increase later in December, unlike the spread between the dealer-placed and directly placed paper reported in the present study. It is hard to conceive that dealer-placed paper becomes systematically more risky in December and December only, compared to directly placed paper. Therefore, we believe that our results are not driven by credit risk.

Third, when it comes to the issuer size, usually only the largest issuers are able to access the CP market. Only 500 to 1500 firms have had outstanding commercial paper at any given time over the last few decades. As to the issue size, it is more likely that firms that regularly place large $\mathrm{CP}$ issues have an in-house $\mathrm{CP}$ operation rather than place their paper through dealers. Issue size is typically related to liquidity. However, it is well known that investors usually buy commercial paper with the intent to hold it to maturity. In case holders need to sell it before maturity, they often can sell it back to the issuer of directly placed paper or to the dealer of dealer-placed paper. Thus, the commitment of the issuer or the dealer to buy the paper back is more important than the issue size. Consistent with this

\footnotetext{
${ }^{13}$ We note that Stigum (1990) suggests that a 5 bps to 10 bps spread in the money markets is an attractive arbitrage opportunity. Accordingly, the spread between AA non-financial CP and AA financial CP is not economically different.
} 
argument, Whitledge and Winters (2015) examine rates on large-bank CDs sold to money market funds and find that $\mathrm{CD}$ rates do not vary with the size of the $\mathrm{CD}$.

Finally, we motivate the paper with the liquidity squeeze in the commercial paper market during the financial crisis to provide the current relevance of the paper, but we do our analysis on an older sample due to data limitations. Specifically, the rate data on dealer-placed and directly placed CP end in 1997. However, some post-crisis data on dealer-placed and directly placed CP is available. Specifically, weekly amounts outstanding of dealer-placed versus directly placed commercial paper are available through 2012 from the Federal Reserve.

Panel A of Figure 3 provides amounts outstanding of dealer-placed and directly placed nonfinancial CP, while Panel B of Figure 3 provides amounts outstanding for dealer-placed and directly placed financial $\mathrm{CP}$. Both show a dramatic decline in the total amounts outstanding across the financial crisis and continuing through the 2009 recessionary period. Toward the end of 2009 Panel A shows an upturn in the total amounts outstanding while Panel B shows a halt in the decline. In both figures the tide was stemmed by a dramatic increase in the amounts outstanding in directly placed CP.

These results suggest that as the economic recovery in the U.S. started at the end of 2009 the $\mathrm{CP}$ issuers moved strongly into directly placed CP and were able to access credit in both the nonfinancial and financial CP markets. Our results are consistent with direct relationships providing more reliable access to credit and suggest that relationships continue to have value in the post-crisis $\mathrm{CP}$ markets.

\section{Conclusion}

Previous empirical literature has identified benefits for direct lending relationships with banks. Diamond (1989) suggests these benefits are derived from the borrower developing a positive 
reputation with the lender. Diamond (1991) suggests that some borrowers develop sufficient reputation to move beyond the intermediated bank lending market to public debt markets, such as commercial paper. Griffiths and Winters (2005a) identify a year-end preferred habitat for liquidity in the commercial paper (CP) market. In addition, the $\mathrm{CP}$ market is segmented into dealer-placed and directly placed paper, which provides a natural experimental setting for us to examine whether direct lending relationships have value for businesses with sufficient reputation to access the public debt markets.

We show that both 30-day dealer-placed and 30-day directly placed CP have year-end rate changes consistent with a year-end liquidity squeeze. That is, when money market investors increase their demand for liquidity, borrowers in both the dealer-placed and directly placed CP markets pay higher rates. However, further analysis shows that the rate increases in the directly placed CP market are smaller than in the dealer-place CP market. We find corroborating evidence for the benefits of direct lending relationships in the market for 90-day CP. Finally, analysis on post-crisis CP amounts outstanding supports that relationship continue to have value.

In summary, our research question is whether benefits exist from direct borrower-lender relationships in public debt markets where borrowers have sufficient credit reputations to overcome the need for intermediated (bank) debt. Our results suggest that such benefits do exist in the form of smaller rate increases during periods of constrained liquidity in public debt markets. 


\section{References}

Athavale, M., and R. Edmister, "The Pricing of Sequential Bank Loans," Financial Review 39 (2004), 231-253.

Berger, A., and G. Udell, “ Relationship Lending and Lines of Credit in Small Firm Finance, Journal of Business, 25 (1995), 21-42.

Bharath, S., Dahiya, D., Saunders, A., and Srinivasan, A, "So what do I get? The bank's view of lending relationships.” Journal of Financial Economics, 85(2) (2007), 368-419.

Blackwell, D., and D. Winters, "Banking Relationships and the Effect of Monitoring on Loan Pricing.” Journal of Financial Research, 20(2) (1997), 275-289.

Burch, T., V. Nanda, and V. Warther, "Does it pay to be loyal? An empirical analysis of underwriting relationships and fees.” Journal of Financial Economics 77 (2005), 673-699.

Diamond, D., "Reputation Acquisition in Debt Markets." Journal of Political Economy 97(4) (1989), 828-862.

Diamond, D., "Monitoring and Reputation: The Choice between Bank Loans and Directly Placed Debt.” Journal of Political Economy 99(4) (1991), 689-721.

Fernando, C., A. May, and W. Megginson, "The value of investment banking relationships: Evidence from the collapse of Lehman Brothers.” Journal of Finance 57 (2012), 235-270.

Griffiths, M., and D. Winters, "The-turn-of-the-year in the money markets: Tests of the risk-shifting window dressing and preferred habitat hypotheses," Journal of Business 78 (2005a), 1337-1364.

Griffiths, M., and D. Winters, "The Year-end Price of Risk in a Market for Liquidity", Journal of Investment Management (2005b), 1-12.

Kacperczyk, M. and P. Schnabl, 2010, When safe proved risky: Commercial paper during the financial crisis of 2007-2009, Journal of Economic Perspectives 24, 29-50.

Kane, E., and B. Malkiel, "Bank Portfolio Allocation, Deposit Variability, and the Availability Doctrine," Quarterly Journal of Economics 79 (1965), 113-134.

Kotomin, V., S. Smith, and D. Winters, "Interest-rate and Calendar-time Effects in Money Market Fund and Bank Deposit Cash Flows", Journal of Economics and Finance, 38(1) (2014), 84-95.

Musto, D., "Portfolio Disclosures and Year-end Price Shifts." Journal of Finance, 52(4) (1997), 1563-1588.

Petersen, M., and R. Rajan, “The Benefits of Lending Relationships: Evidence from 
Small Business Data.” Journal of Finance, 49 (1994), 3-37.

Stigum, M., The Money Market, 1990, Third Edition, Dow Jones-Irwin.

Whitledge, M., and D. Winters, 2015, The price of liquidity: CD rates charged by money market funds, Journal of Banking and Finance 54, 104-114.

Yasuda, A., "Do Bank Relationships Affect the Firm's Underwriter Choice in the Corporate-Bond Underwriting Market?” Journal of Finance, 60 (2005), 1259-1292. 


\section{Table 1}

Panel A. Mean Commercial Paper and Three-month T-bill Rates, 1983-1996.

\begin{tabular}{llllll}
\hline Average Rate, \% & $\begin{array}{l}\text { 30-day } \\
\text { Dealer }\end{array}$ & $\begin{array}{l}\text { 30-day } \\
\text { Direct }\end{array}$ & $\begin{array}{l}\text { 90-day } \\
\text { Dealer }\end{array}$ & $\begin{array}{c}\text { 90-day } \\
\text { Direct }\end{array}$ & $\begin{array}{l}\text { 3-month } \\
\text { T-bill }\end{array}$ \\
\hline Entire sample period & 6.686 & 6.588 & 6.699 & 6.515 & 6.155 \\
January - November & 6.673 & 6.588 & 6.703 & 6.530 & 6.173 \\
December & 6.828 & 6.585 & 6.660 & 6.356 & $5.957 *$ \\
\hline
\end{tabular}

Panel B. Spread between Dealer-placed and Directly placed Commercial Paper Rates

\begin{tabular}{lll}
\hline Average Spread, \% & \multicolumn{1}{c}{ 30-day } & \multicolumn{1}{c}{ 90-day } \\
\hline Entire sample period & 0.099 & 0.185 \\
January - November & 0.087 & 0.174 \\
December & $0.234 * * *$ & $0.296 * * *$ \\
\hline
\end{tabular}

$* * *, * *, *$ December statistics is significantly different from January-November statistics at the $1 \%$, $5 \%$, or $10 \%$ level, respectively (using two-tailed t-tests for mean equality). 
Table 2. Panel A presents the regression output for daily commercial paper rate changes (Equation 1):

$\Delta R_{t}=a_{0}+a_{1} \Delta$ Tbill $_{t}+\alpha_{2}$ JanEnd $+\alpha_{3}$ FebBgn $+\cdots+a_{22}$ NovEnd $+a_{23}$ DecBgn $+a_{24}$ YrEnd $+a_{25}$ YrBgn $+\varepsilon_{t}$ The four regressions in Panel A are for the changes (in bps) in the 30-day dealer-placed commercial paper rates, 30-day directly placed commercial paper rates, 90-day dealer-placed commercial paper rates, and 90-day directly placed commercial paper rates.

Panel B presents the regression output for daily changes in the spread between dealer-placed and directly placed commercial paper rates (Equation 2):

$$
\Delta \text { Spr }_{t}=a_{0}+a_{1} \text { JanEnd }+\alpha_{2} \text { FebBgn }+\cdots+a_{21} \text { NovEnd }+a_{22} \text { DecBgn }+a_{23} \text { YrEnd }+a_{24} \text { YrBgn }+\varepsilon_{t}
$$

The two regressions in Panel B are for the changes (in bps) in the 30-day spread and the 90-day spread.

$\Delta$ Tbill is the change in the 3-month T-bill yield in basis points; JanEnd is a dummy variable that equals 1 on the last two trading days of January, and so on for the end of every month except December; FebBgn is a dummy variable that equals 1 on the first two trading days of February, and so on for the beginning of every month except January; YrEnd is a dummy variable that equals 1 on the last two trading days of the year, and $\mathrm{YrBgn}$ is a dummy variable that equals 1 on the first two trading days of the year.

The regressions are OLS with the White's adjustment. The estimation period is 1983-1996.

\begin{tabular}{|c|c|c|c|c|c|c|}
\hline 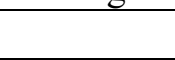 & \multicolumn{4}{|c|}{ Panel A. CP Rate Changes, bps } & \multicolumn{2}{|c|}{ Panel B. CP Spread Changes, bps } \\
\hline Variable & $\begin{array}{l}\text { 30-day } \\
\text { Dealer }\end{array}$ & $\begin{array}{l}\text { 30-day } \\
\text { Direct }\end{array}$ & $\begin{array}{l}\text { 90-day } \\
\text { Dealer }\end{array}$ & $\begin{array}{l}\text { 90-day } \\
\text { Direct }\end{array}$ & $\begin{array}{l}\text { 30-day } \\
\text { Dlr-Dir }\end{array}$ & $\begin{array}{l}\text { 90-day } \\
\text { Dlr-Dir }\end{array}$ \\
\hline Intercept & -0.1 & -0.3 & 0.0 & -0.1 & 0.2 & 0.1 \\
\hline$\Delta$ Tbill & $0.3 * * *$ & $0.4 * * *$ & $0.3 * * *$ & $0.2 * * *$ & --- & --- \\
\hline JanEnd & $1.0 *$ & 2.5 & 0.1 & 0.4 & -1.6 & -0.2 \\
\hline FebBgn & -0.4 & 0.0 & -0.2 & 0.4 & -0.5 & -0.5 \\
\hline FebEnd & $2.0^{*}$ & 2.2 & 0.9 & 1.1 & -0.3 & -0.2 \\
\hline MarBgn & $1.6 * *$ & 1.6 & $1.3 * *$ & 0.6 & 0.0 & 0.8 \\
\hline MarEnd & $2.1 * *$ & 0.1 & 1.2 & -0.4 & 2.0 & 1.5 \\
\hline AprBgn & $-2.1 * *$ & 1.7 & $-1.4 * *$ & 1.2 & $-3.8 * *$ & $-2.5 * * *$ \\
\hline AprEnd & 1.3 & $3.2 * * *$ & 0.7 & 0.6 & $-1.9 * *$ & 0.1 \\
\hline MayBgn & 1.0 & $2.0 * *$ & 0.6 & 0.3 & $-1.1^{*}$ & 0.4 \\
\hline MayEnd & $1.7 * *$ & 1.3 & $1.9^{* *}$ & 1.5 & 0.4 & 0.5 \\
\hline JunBgn & $0.6^{* * *}$ & -0.3 & -0.8 & -1.3 & 1.0 & 0.4 \\
\hline JunEnd & $1.9 * * *$ & -1.1 & 0.9 & 0.6 & 3.1 & 0.2 \\
\hline JulBgn & $-3.3 * * *$ & -1.6 & $-2.6 * *$ & $-3.6^{*}$ & -1.7 & 1.0 \\
\hline JulEnd & 0.7 & -0.1 & 0.3 & -0.1 & 0.8 & 0.4 \\
\hline AugBgn & 1.2 & $3.4^{* *}$ & 1.2 & 0.7 & $-2.1^{*}$ & 0.4 \\
\hline AugEnd & 0.8 & -0.1 & 0.3 & 0.9 & $-1.0 *$ & -0.6 \\
\hline SepBgn & $1.7 * * *$ & $3.9 * * *$ & $1.6^{* *}$ & 0.6 & $-2.2 * * *$ & 0.9 \\
\hline SepEnd & $3.4 * * *$ & $6.4^{*}$ & $2.4^{* *}$ & 1.0 & -2.9 & 1.4 \\
\hline OctBgn & $-3.6 * * *$ & $-2.3 * * *$ & -0.2 & 1.2 & -1.4 & -1.4 \\
\hline OctEnd & -0.1 & -0.6 & -0.9 & 0.6 & 0.5 & -1.5 \\
\hline NovBgn & 0.5 & 0.5 & -0.2 & -0.2 & 0.0 & 0.1 \\
\hline NovEnd & $2.8 *$ & $3.5 * * *$ & $4.2 *$ & $2.8 * *$ & -0.6 & 1.2 \\
\hline DecBgn & $14.7 * * *$ & $11.8 * * *$ & 0.1 & 0.0 & 2.7 & 0.3 \\
\hline YrEnd & $-6.8^{*}$ & $-5.2 * *$ & $-5.6 * *$ & -1.0 & -1.6 & $-4.6 * *$ \\
\hline YrBgn & $-18.2 * * *$ & $-6.3 * * *$ & $-7.0 * * *$ & -1.0 & $-12.0^{*}$ & $-5.8^{*}$ \\
\hline F-stat & $29.3 * * *$ & $13.8 * * *$ & $22.9 * * *$ & $7.6 * * *$ & $3.4 * * *$ & $2.0 * * *$ \\
\hline Adj. $\mathrm{R}^{2}$ & $16.9 \%$ & $8.4 \%$ & $13.7 \%$ & $4.5 \%$ & $1.6 \%$ & $0.7 \%$ \\
\hline
\end{tabular}

$* * *, * *$, and $*$ denote statistical significance at the $1 \%, 5 \%$, and $10 \%$ level, respectively. 


\section{Table 3. Spreads on Days -25 to +5 relative to the end of the year and all other ("regular") days.}

We first compute the spread between each of the two types of CP rates and the three-month T-bill rate as well as between the two different types of CP rates, dealer-placed and directly placed paper, in the 30-day and 90day maturities, for each trading day in our sample period, 1983-1996. Then for each trading day from -25 to +5 relative to the year-end (our chosen turn-of-the-year window) we calculate the average daily spread over the sample period (e.g., the average dealer-direct 30-day CP spread on day -25 is the average of all such spreads on day -25 over the 14-year study period), as well as the average spread on all other ("regular") days.

\begin{tabular}{|c|c|c|c|c|}
\hline \multirow[b]{3}{*}{$\begin{array}{l}\text { Trading Day } \\
\text { relative to Y-end }\end{array}$} & \multicolumn{4}{|c|}{ Average Spreads, bps } \\
\hline & \multicolumn{2}{|c|}{ CP-3-month T-bill } & \multicolumn{2}{|c|}{ Dealer CP-Direct CP } \\
\hline & 30-day Dealer & 30-day Direct & 30-day & 90-day \\
\hline "Regular" days & 49.9 & 41.3 & 8.6 & 17.4 \\
\hline-25 & 44.1 & 32.9 & $13.1 *$ & 14.0 \\
\hline-24 & 43.6 & 29.4 & $12.6 *$ & 20.8 \\
\hline-23 & 47.7 & 33.7 & $14.0 * * *$ & $23.4^{*}$ \\
\hline-22 & 48.5 & 34.9 & $13.1 * *$ & $25.6^{* *}$ \\
\hline-21 & $71.6 * * *$ & 50.5 & $21.1 * * *$ & 22.7 \\
\hline-20 & $78.6^{* * *}$ & $57.0 *$ & $21.6^{* * *}$ & $22.9 *$ \\
\hline-19 & $78.3 * * *$ & $57.1 *$ & $21.2 * * *$ & $24.1 *$ \\
\hline-18 & $73.7 * * *$ & $60.9 * *$ & $12.8 * *$ & $24.8 * *$ \\
\hline-17 & $71.9 * * *$ & $57.6 *$ & $14.2 * * *$ & $27.7 * * *$ \\
\hline-16 & $74.8 * * *$ & $60.4 * *$ & $14.4 * * *$ & $26.1 * * *$ \\
\hline-15 & $74.4^{* * *}$ & $61.6^{* *}$ & $12.8 * *$ & $27.7 * * *$ \\
\hline-14 & $76.9 * * *$ & $59.7 * *$ & $17.1 * * *$ & $28.1 * * *$ \\
\hline-13 & $77.6 * * *$ & $61.7 * *$ & $15.9 * * *$ & $28.4 * * *$ \\
\hline-12 & $81.0 * * *$ & $66.2 * * *$ & $14.8 * * *$ & $31.1 * * *$ \\
\hline-11 & $84.9 * * *$ & $64.6 * * *$ & $20.3 * * *$ & $30.5 * * *$ \\
\hline-10 & $90.1 * * *$ & $68.1 * * *$ & $22.0 * * *$ & $32.4 * * *$ \\
\hline-9 & $89.7 * * *$ & $68.6^{* * *}$ & $21.1 * * *$ & $31.7 * * *$ \\
\hline-8 & $92.4 * * *$ & $67.9 * * *$ & $24.5 * * *$ & $27.9 * * *$ \\
\hline-7 & $98.4 * * *$ & $75.5^{* * *}$ & $22.9 * * *$ & $34.4 * * *$ \\
\hline-6 & $101.2 * * *$ & $71.5 * * *$ & $29.7 * * *$ & $29.9 * * *$ \\
\hline-5 & $101.9 * * *$ & $65.2 * * *$ & $30.2 * * *$ & $32.4 * * *$ \\
\hline-4 & $106.6 * * *$ & $68.9 * * *$ & $37.6^{* * *}$ & $34.5 * * *$ \\
\hline-3 & $107.6 * * *$ & $67.4 * * *$ & $40.2 * * *$ & $39.1 * * *$ \\
\hline-2 & $106.2 * * *$ & $63.4 * * *$ & $42.6^{* * *}$ & $36.3 * * *$ \\
\hline-1 & $94.9 * * *$ & $57.5^{*}$ & $37.4 * * *$ & $29.9 * * *$ \\
\hline+1 & 59.9 & $55.5^{*}$ & $4.4^{* * *}$ & 17.8 \\
\hline+2 & 54.4 & 43.8 & 10.6 & 19.1 \\
\hline+3 & 51.9 & 40.0 & $11.9 *$ & 18.6 \\
\hline+4 & 49.7 & 39.4 & 10.3 & 16.4 \\
\hline+5 & 46.8 & 35.3 & 11.5 & 14.5 \\
\hline
\end{tabular}

$* * *, * *$, and $*$ denote that the average spread on a given day in the turn-of-the-year window is significantly different (using a two-tailed t-test) from the average spread on "regular" (all other) days (reported in the first row) at the $1 \%, 5 \%$, or $10 \%$ level, respectively. 
Figure 1. Average Intrayear Spreads

A. Average Intrayear Spreads between Commercial Paper and T-bill Rates

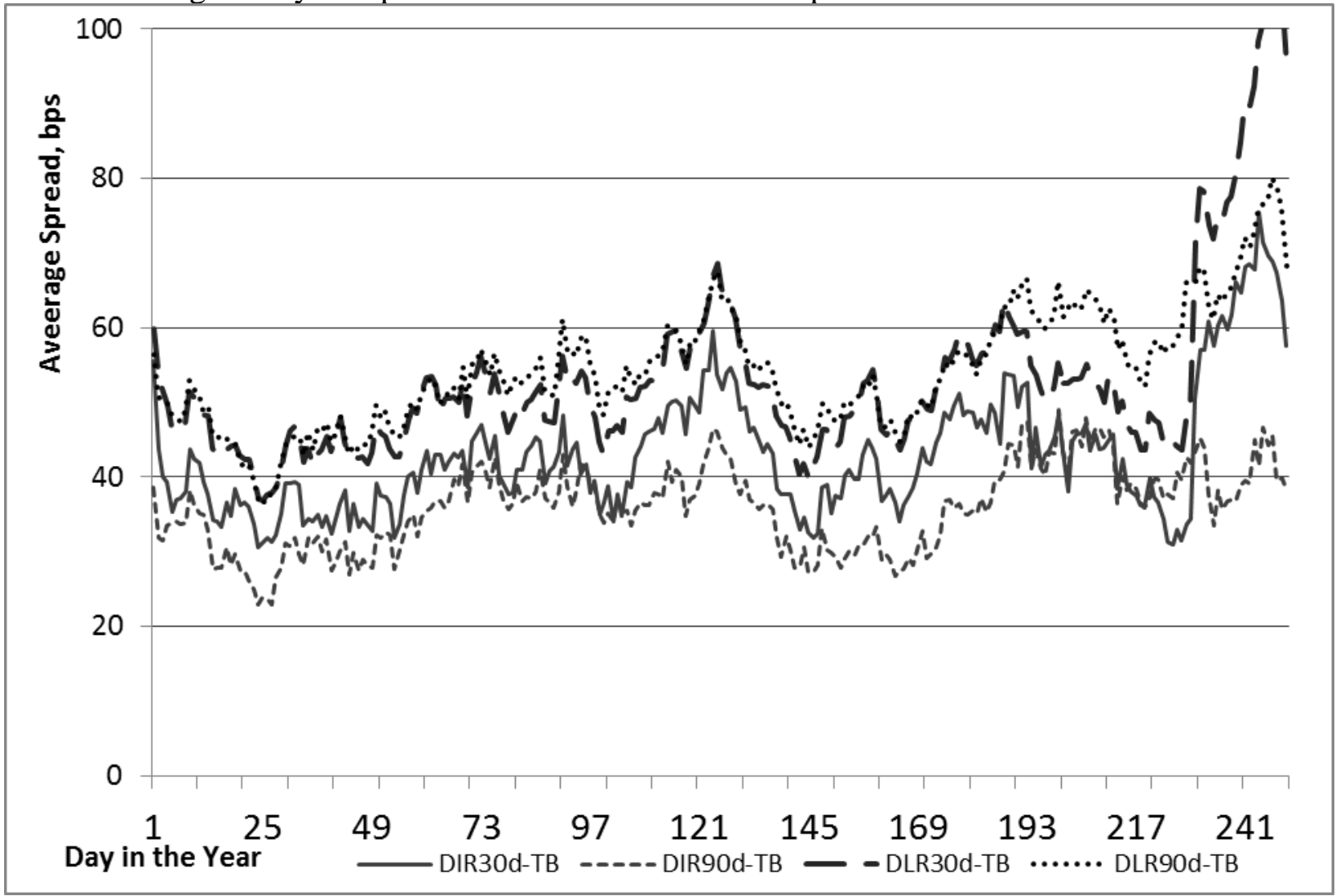


B. Average Intrayear Spreads between Dealer-placed and Directly Placed CP Rates

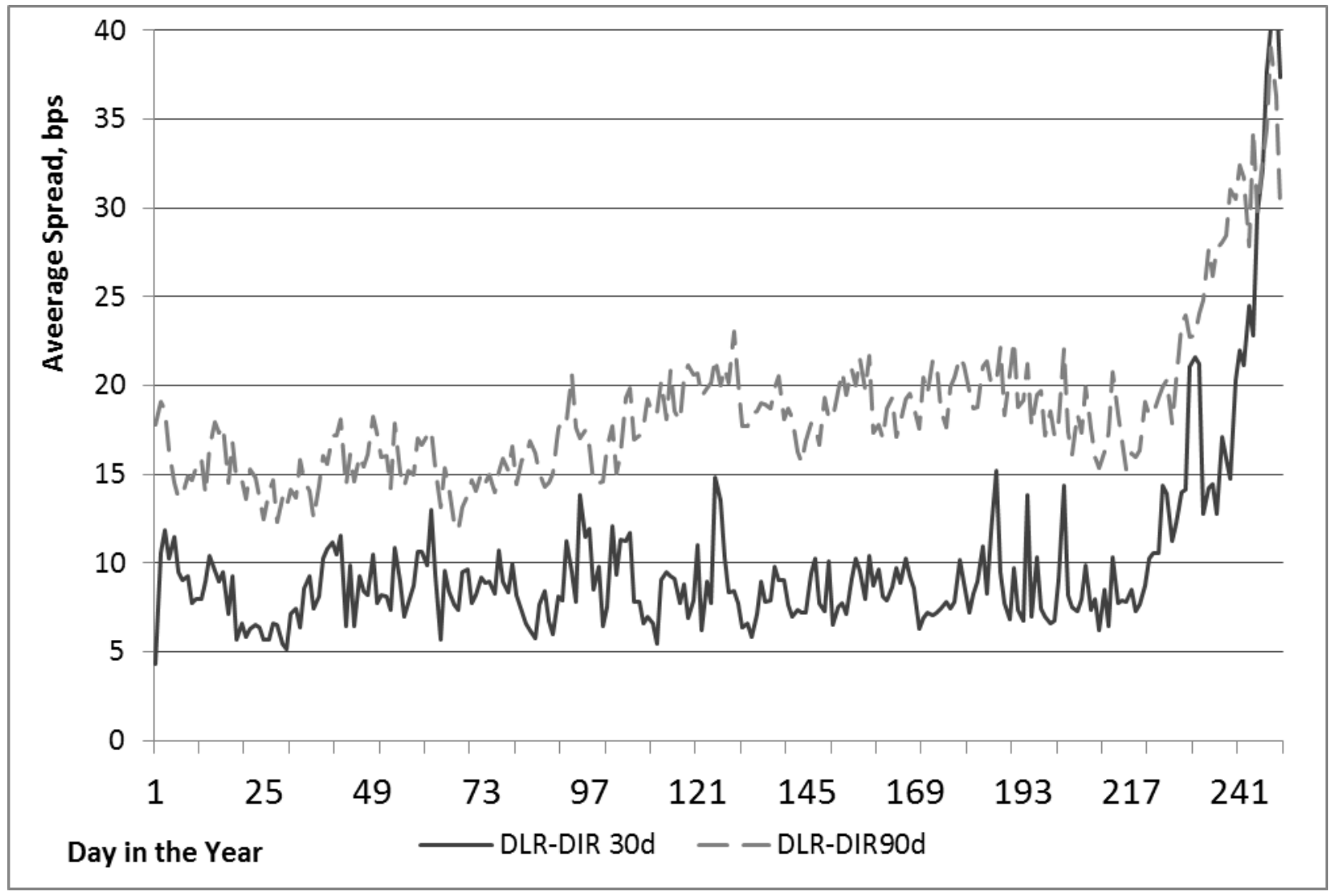


Figure 2. Differences between the average daily spread on each of the trading days from -25 through +5 relative to the year-end and the average daily spread on all other trading days, 1983-1996, in basis points. Day -1 is the last trading day of the year, and day +1 is the first trading day of the new year.

A. Spread Differences for the Spreads between 30-day Commercial Paper and 3-month T-bill Rates.

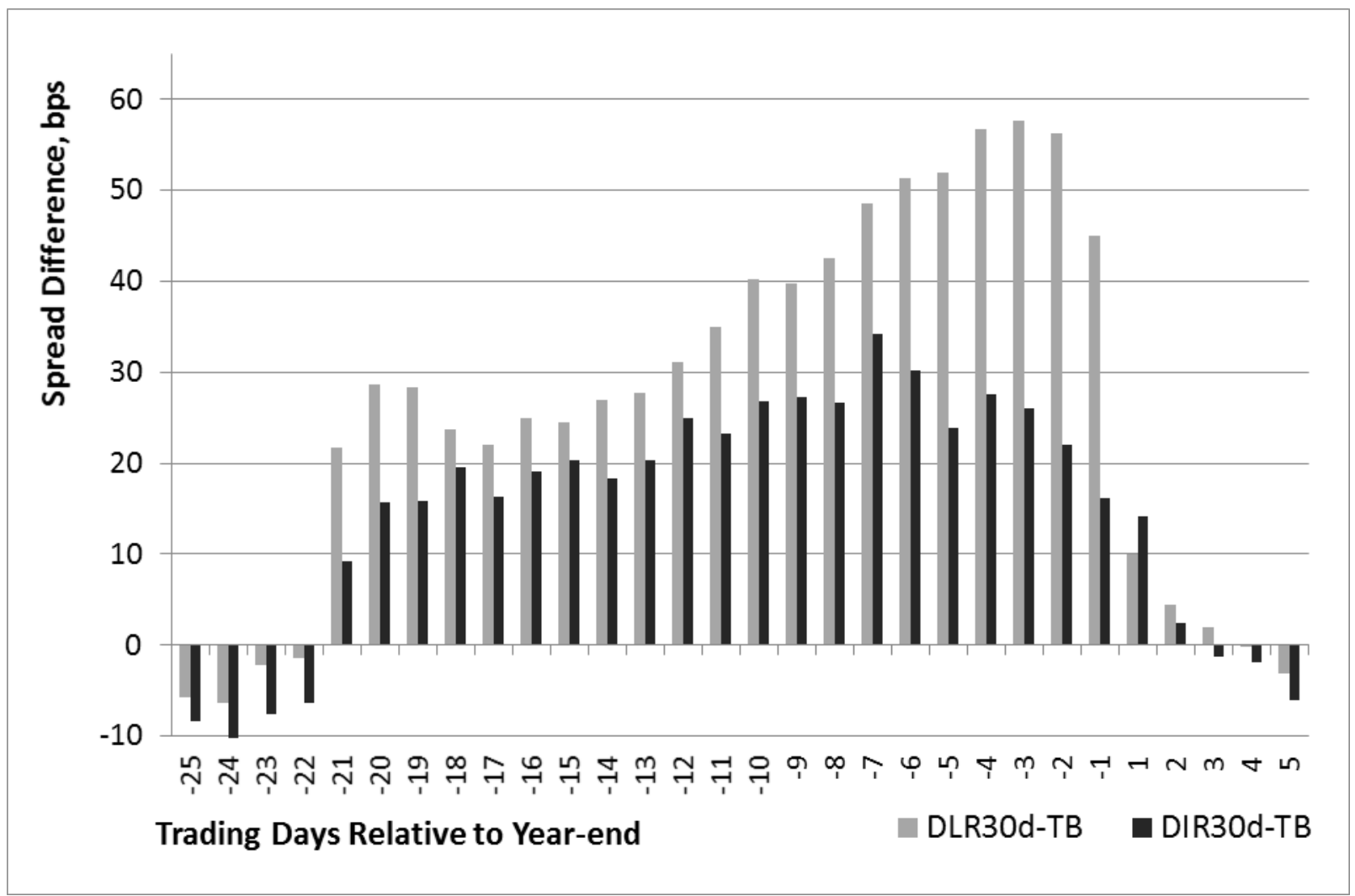


B. Spread Differences for the Spreads between Dealer-placed and Directly Placed Commercial Paper Rates.

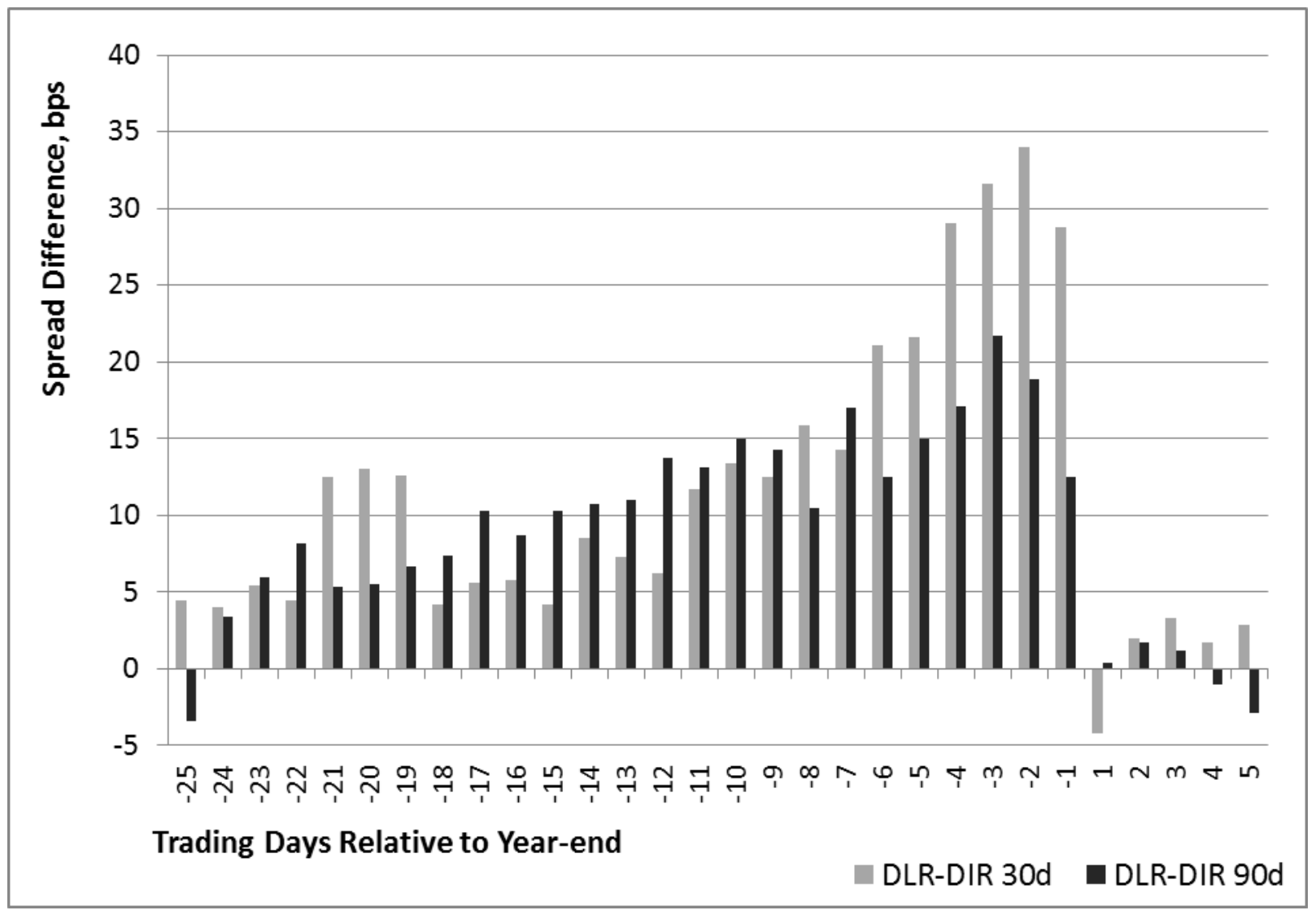


Figure 3. Outstanding Commercial Paper, January 2001 - June 2012.

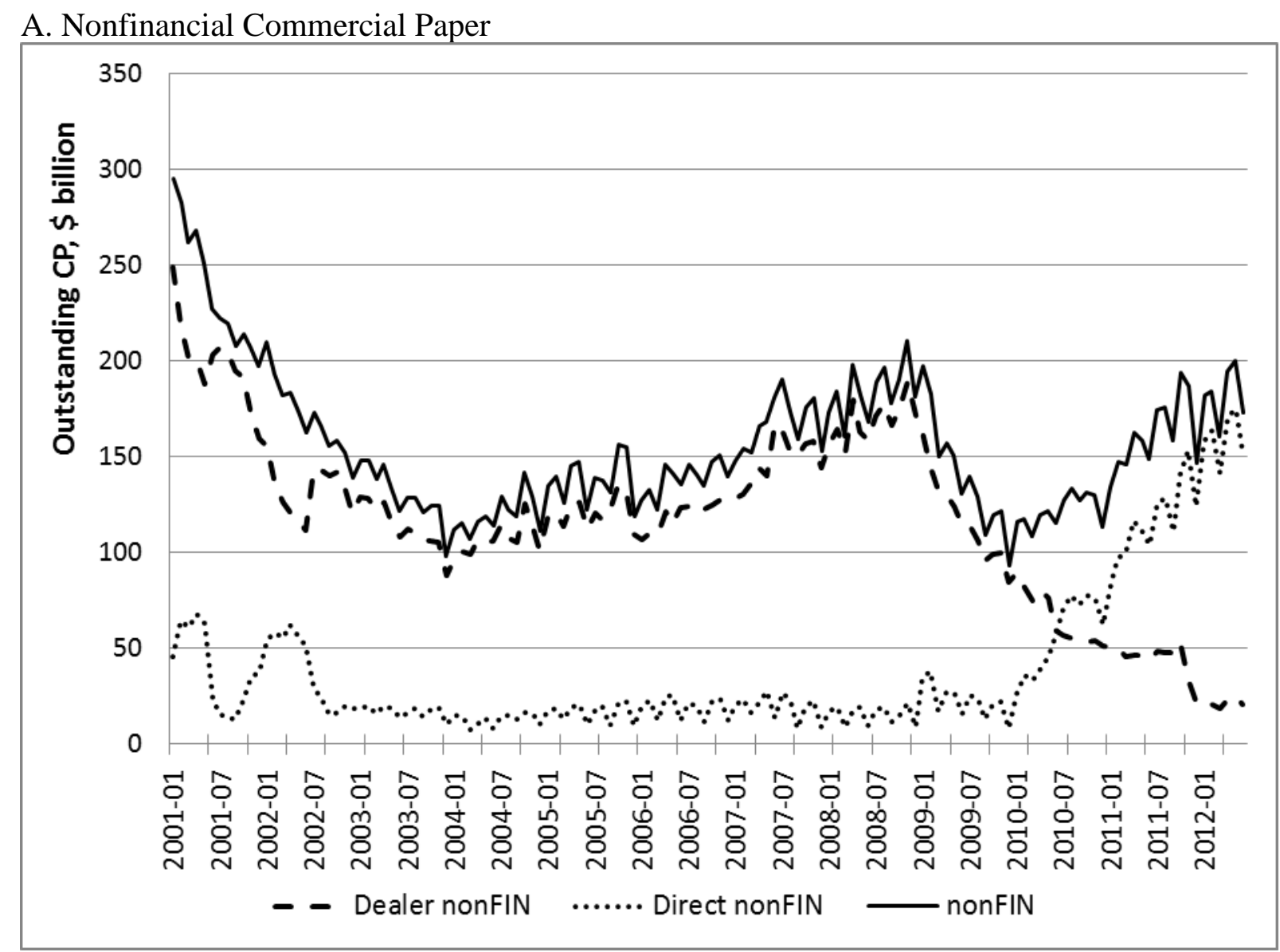


B. Financial Commercial Paper

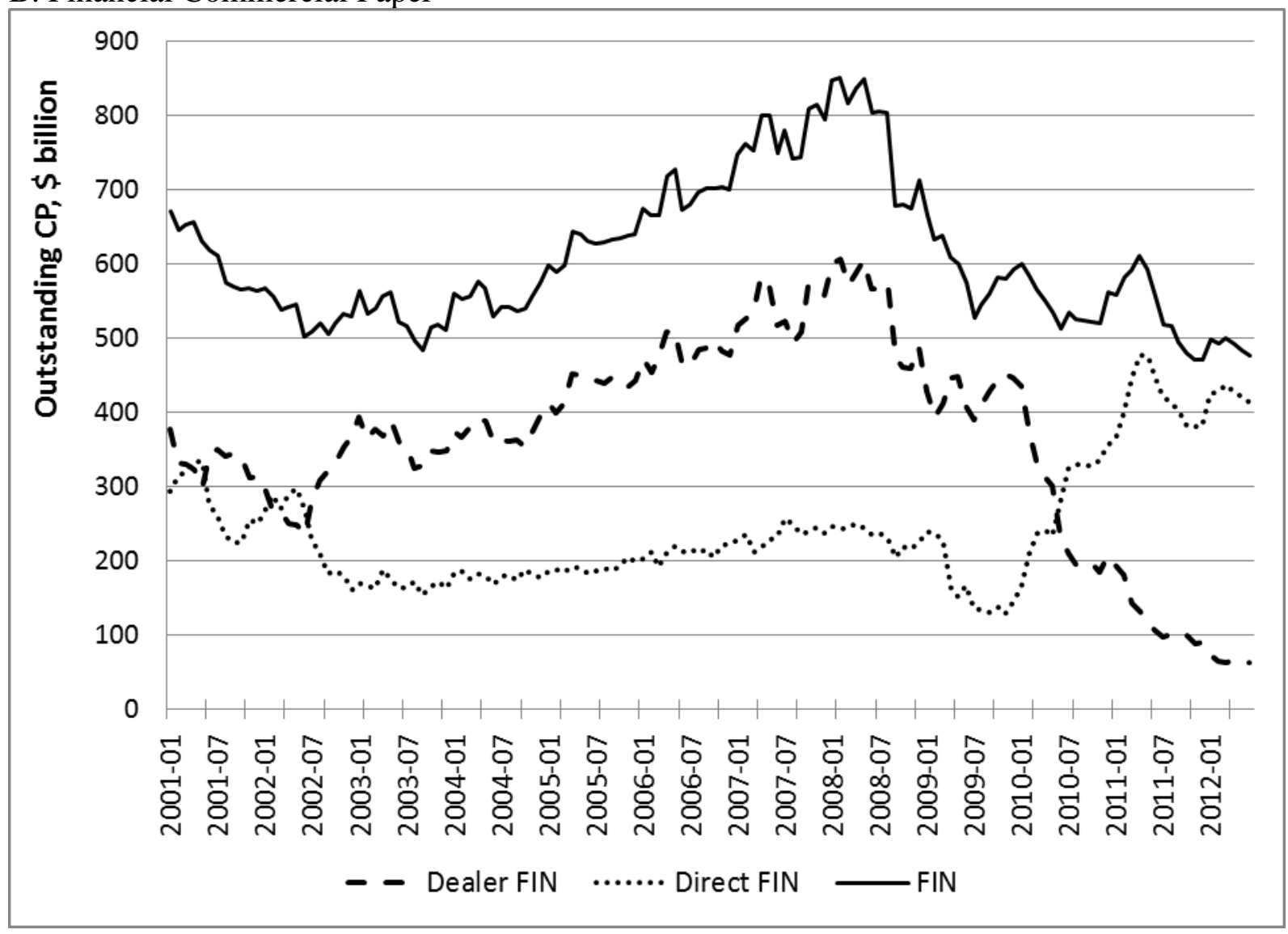

